\title{
Deciphering the Role of Hydrogen Bonding in Enhancing pDNA-Polycation Interactions
}

\author{
Lisa E. Prevette, ${ }^{1}$ Tom E. Kodger, ${ }^{2}$ Theresa M. Reineke, ${ }^{*}{ }^{1}$ MatthewL. Lynch $*^{2}$
}

University of Cincinnati, Department of Chemistry, P.O. Box 210172, Cincinnati, OH 45221-0172 and

The Procter \& Gamble Company, Corporate Research Division, Miami Valley Laboratories, 11810 East

Miami River Road, Cincinnati, OH 45252-1038

Email: theresa.reineke@uc.edu

SUPPORTING INFORMATION 
Time (min)
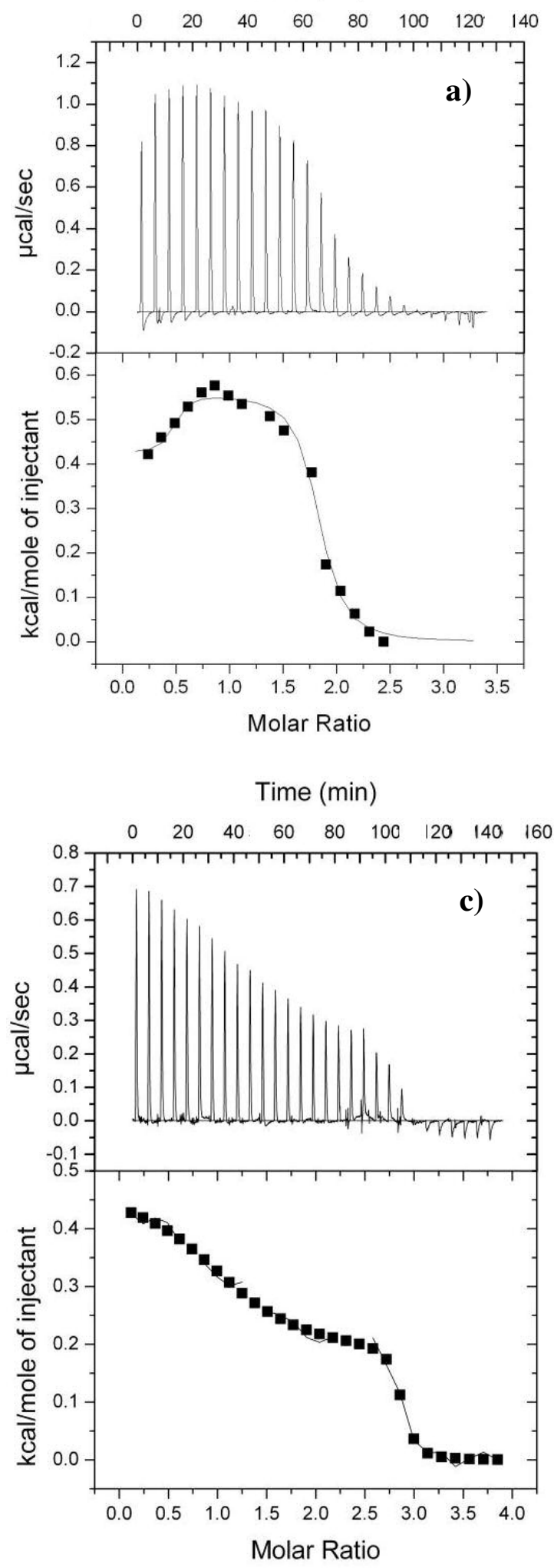

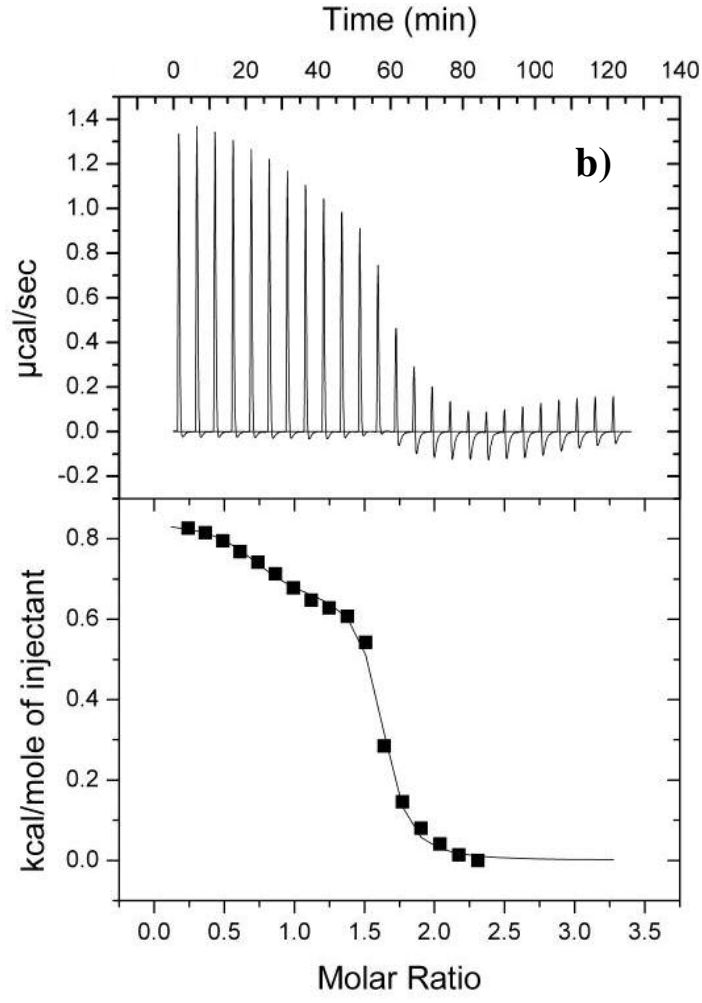

Figure S1. Isothermal Titration Calorimetry (ITC) thermograms for $5.5 \mathrm{mM}$ G4 (a), D4 (b), and M4 (c) titrated into $0.31 \mathrm{mM}$ pDNA. Injection points containing heat of aggregation were subtracted from the normalized data (bottom curve) before nonlinear least squares fitting to a standard twe site model with Origin 7.0. Since aggregation occurred at different N/P ratios for the three PGAAs shown above, the number of points subtracted due to this effect varies. 

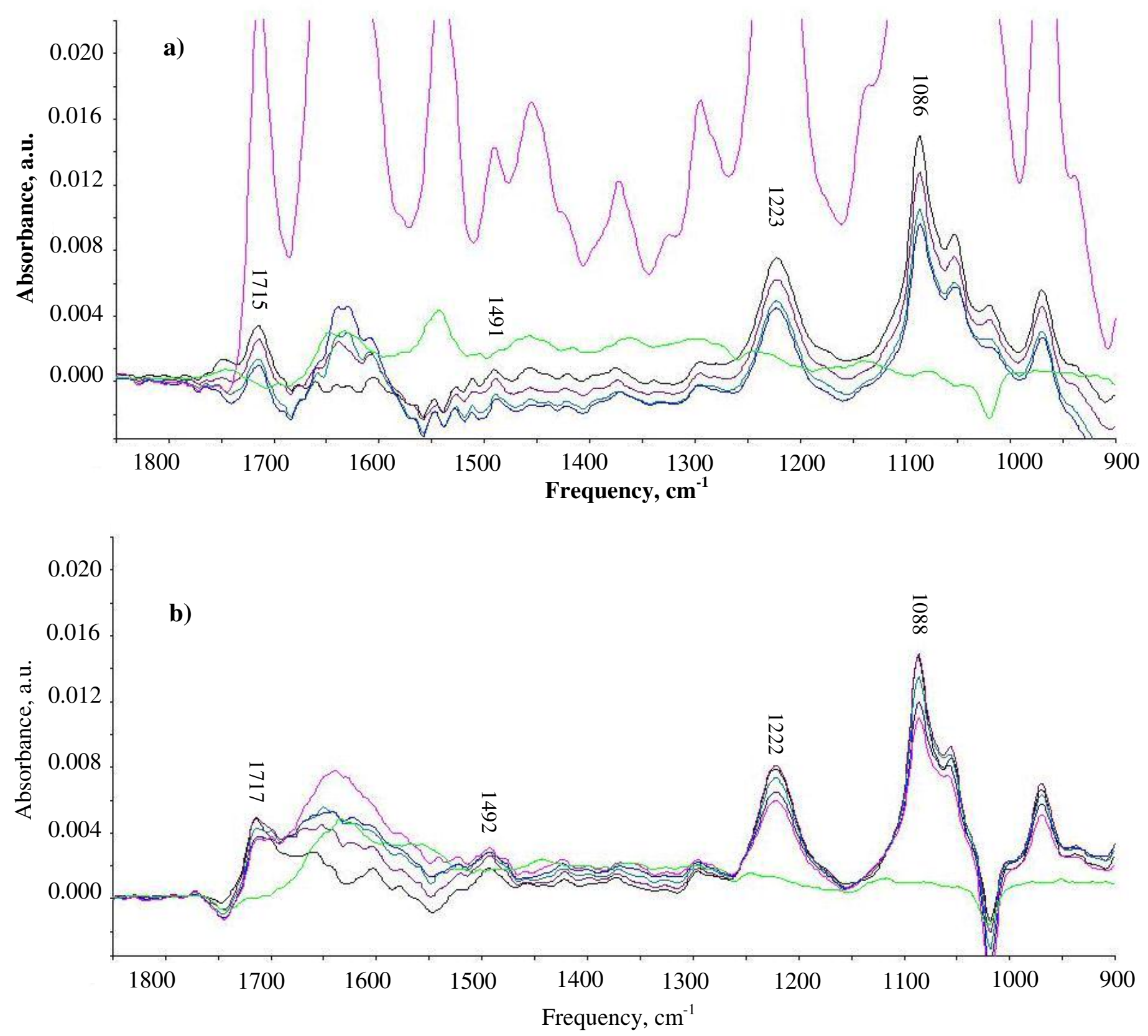

Figure S2. FTIR spectra of T4 (a), and M4 (b) polyplexes formed at N/P ratios of 0 (DNA only) $0.25 \longleftarrow, 0.75-, 1.3-$, and $2.5-$ in $10 \mathrm{mM}$ Tris buffer $(\mathrm{pH} 7.4)$ at $25^{\circ} \mathrm{C}$. Polymer only spectra are shown overlapping - . 


\section{HYDROPHOBICITY MEASUREMENTS}

Methods. Solutions of $4 \mathrm{mg} / \mathrm{mL}$ of each poly(glycoamidoamine) were made in ultrapure water. One $\mathrm{mL}$ of each of these solutions was added to $1 \mathrm{~mL}$ of 1-octanol, mixed thoroughly, and allowed to equilibrate for $30 \mathrm{~min}$. After equilibration, the water layer was removed and its refractive index was analyzed via gel permeation chromatography with a low molecular weight cationic column at $25{ }^{\circ} \mathrm{C}$ using a mobile phase of pH 5 water. (Refractive index is linearly related to concentration.) The area under each refractive index curve was compared to that of five standards $(10,8,6,4$ and $2 \mathrm{mg} / \mathrm{mL})$ of the respective PGAA to determine the concentration of polymer in the unknown water layer.

Results. The refractive index curves for the standards and unknown solutions of each poly(glycoamidoamine) are shown in Figure S3. All four PGAAs showed approximately $4 \mathrm{mg} / \mathrm{mL}$ concentration; therefore, within the error of the instrument, we can conclude that $100 \%$ of the polycations were dispersed into the water layer. Thus, G4, T4, D4, and M4 each have an octanol-water partition coefficient of 0 . This is expected, considering the many hydroxyl groups, secondary amines and amides along the polymer backbone. 

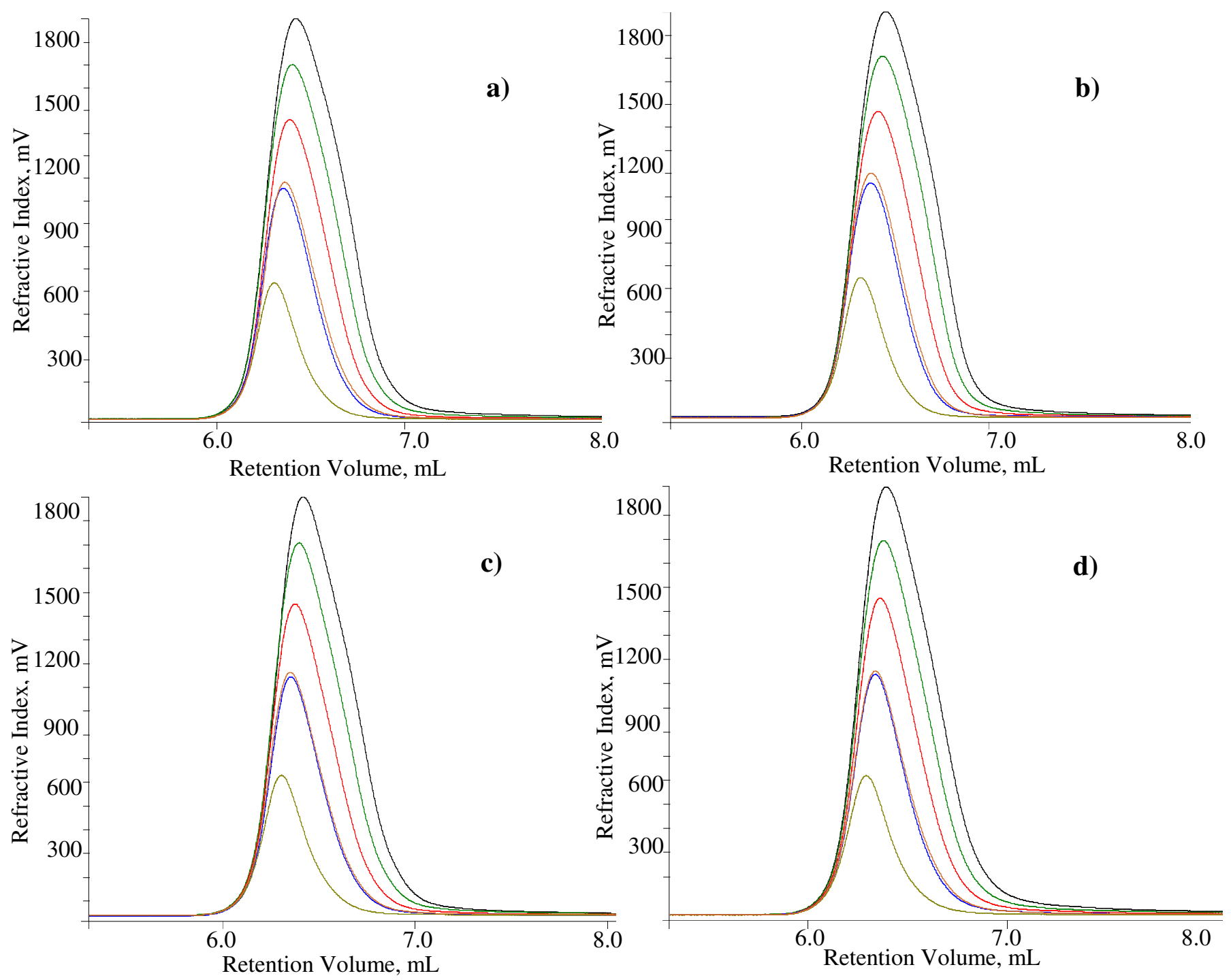

Figure S3. Refractive index curves for G4 (a), T4 (b), D4c), and M4 (d) in water as determined by gel permeation chromatography. Polymer standard solutions of $10 \mathrm{mg} / \mathrm{mL} \longrightarrow, 8 \mathrm{mg} / \mathrm{mL}-, 6$ $\mathrm{mg} / \mathrm{mL} \longrightarrow, 4 \mathrm{mg} / \mathrm{mL} \longrightarrow$ and $2 \mathrm{mg} / \mathrm{mL} \longrightarrow$. The unknown sample isshown —. 